\title{
A special discovery of pancreatic adenocarcinoma by Sister Mary-Jo- seph's Nodule: what is the prognosis?
}

\author{
Mohamed Ali Chaouch ${ }^{\mathrm{a}^{*}}$, Asma Chaouch ${ }^{\mathrm{a}}$, Karim Nacef ${ }^{\mathrm{a}}$, Moez Boudokhane ${ }^{\mathrm{a}}$ \\ ${ }^{a}$ Department of General Surgery, Tahar Sfar Hospital, Mahdia, Tunisia.
}

\begin{abstract}
Cutaneous metastases of visceral tumours are uncommon and might have umbilical and/or extra umbilical locations. The umbilical location, also named «Nodule of Sister Mary-Joseph» among 7 to $9 \%$ is secondary to a pancreatic tumour. In this article, we reported a case of a 50-years-old man presenting pancreatic cancer discovered by umbilical nodules and weight loss noticed 3 months earlier treated by palliative chemotherapy. We report this case of a rare presentation of cutaneous metastases of pancreatic disease to insist on its bad prognosis level.

Keywords: Cutaneous metastasis; pancreatic cancer; chemotherapy; nodule of Sister Mary Joseph
\end{abstract}

\section{INTRODUCTION}

Cutaneous metastases of visceral tumours are uncommon. It can be umbilical and or extra umbilical. The umbilical location is known as the "Nodule of Sister Mary-Joseph" (NSMJ). It is described for the first time in 1949 by Sir Hamilton Bailey ${ }^{[1]}$ and since about 600 cases of NSMJ have been published which only 7 to $9 \%$ are secondary to a pancreatic tumour ${ }^{[2]}$. We report this case of a rare presentation of cutaneous metastases of pancreatic disease to insist on its bad prognosis level.

\section{CASE REPORT}

A 50-year-old men, with a familial history of an idiopathic mega-oesophagus in the father and adenocarcinoma of the prostate in the paternal uncle, consult for umbilical nodules and a weight loss for 3 months. Physical examination reveals an irregular, indurated, umbilical nodules measuring 2 × $1.5 \mathrm{~cm}$ (Figure 1). Biological exams show anaemia at $9 \mathrm{~g} / \mathrm{dl}$. Abdominal ultrasound shows an umbilical hypoechoic heterogeneous non-vascularized mass.

An abdominal CT scan revealed a hypodense tissue mass

\footnotetext{
*Corresponding author: Dr. Mohamed Ali Chaouch Mailing address: Department of general surgery, Tahar Sfar Hospital, Mahdia, Tunisia.

E-mail: Docmedalichaouch@gmail.com

Received: 24 December 2019 Accepted: 12 February 2020
}

at the body and tail of the pancreas measuring $59 \times 48$ $\mathrm{x} 44 \mathrm{~cm}$ with fuzzy limits and little enhancement after injection with heterogeneous necrotic appearance (Figure 2). This invades the splenic vein. Hypodense epiploic masses of $26 \mathrm{~mm}$ per pancreatic in contact with the gastric wall and $11.4 \mathrm{~mm}$ peri-umbilical suggest nodules of carcinomatosis. The patient had many biopsies of this umbilical lesion. Anatomopathological examination with an immunohistochemical study concluded with cutaneous metastasis of pancreatic adenocarcinoma. The diagnosis of a tumour of the body and the tail of the pancreas with umbilical and peritoneal metastases was

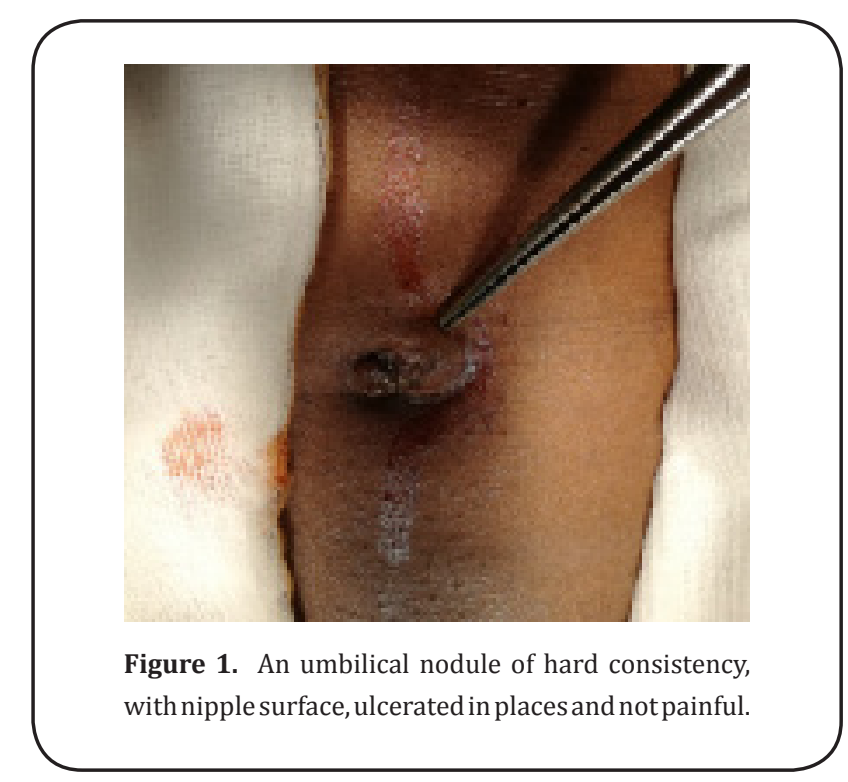




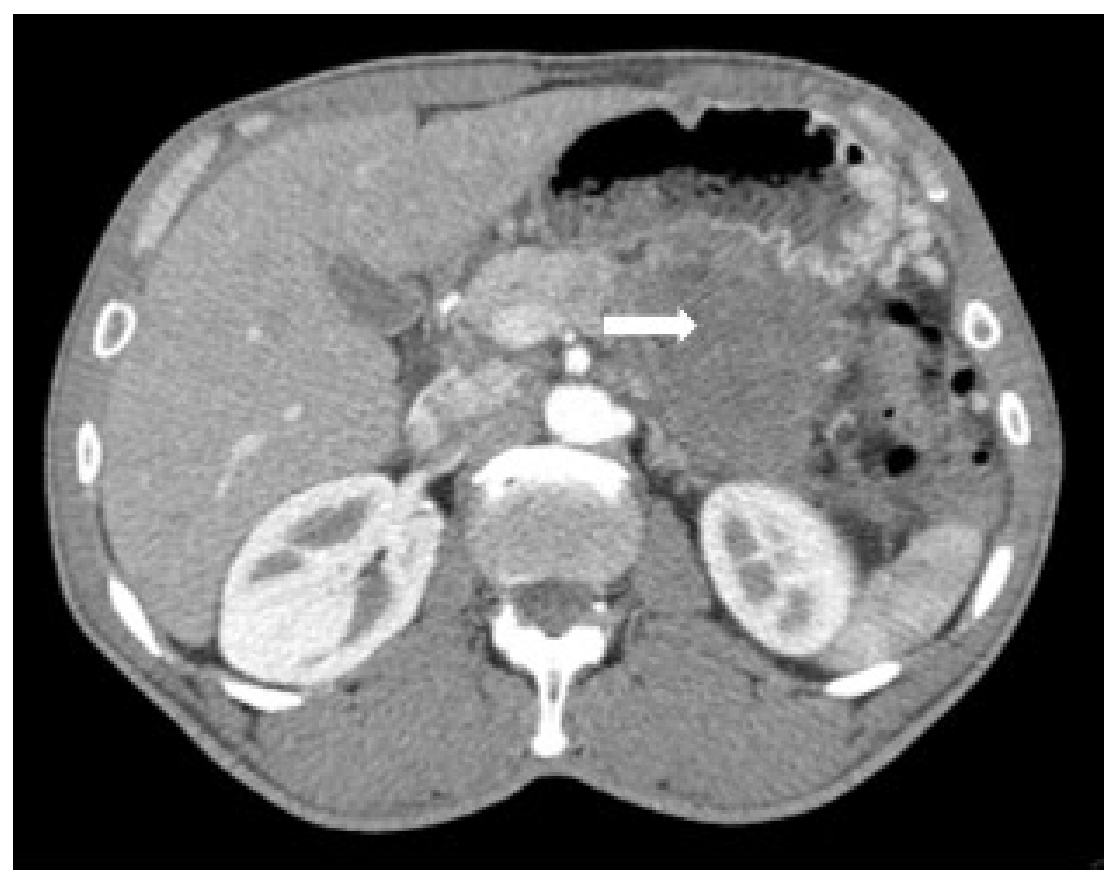

Figure 2. An abdominal CT-scan showing a necrotic pancreatic tumor (white arrow).

retained. The patient had palliative chemotherapy with Cisplatin. The patient was dead after six months.

\section{DISCUSSION}

Sister Mary-Joseph (1856-1939) was an assistant nurse to the surgeon William J. Mayo, son of William Worrall Mayo, founder of the Mayo Clinic in Rochester, was the first to notice the association of an umbilical nodule with an abdominal tumour during the examination of patients undergoing laparotomy ${ }^{[3]}$. These nodules are present in 1 to $3 \%$ of patients with abdominal tumour ${ }^{[4]}$. They represent $30 \%$ of umbilical tumours and they are witnesses of adenocarcinoma in $90 \%$ of cases ${ }^{[5]}$. But they can also be associated with squamous cell carcinoma, melanoma or sarcoma. The gastrointestinal tract is the most common origin of the primary tumour followed by gynaecological localization ${ }^{[6]}$. The most-reported digestive origins in descending order are stomach (26\%), colon (10\%) and pancreas (7\% ${ }^{[6]}$. Primary tumor cannot be found in $15 \%$ of cases ${ }^{[7,8]}$. The pathophysiology remains unclear and several hypotheses have been proposed. Direct extension of peritoneal lesions remains the most common mechanism. Hematogenous dissemination or lymphatic extension along with ligaments of embryonic or iatrogenic origin during laparoscopy is reported ${ }^{[9]}$. It concerns essentially adults with equal sex ratio ${ }^{[2]}$. It is known that pancreatic tumor remains asymptomatic for a long time. Then, they are usually discovered at an advanced stage ${ }^{[2,10]}$. The umbilical cutaneous metastasis is seen more frequently than other cutaneous localizations. Patient survival only a few months ${ }^{[2]}$. Admittedly, the NSMJ is a sign of neoplastic progression or recurrence remains a sign prognosis pejorative even suggesting the therapeutic abstention. However, some studies ${ }^{[11,12]}$, confirming our results, have led to the conclusion that early diagnosis with combined surgery-chemotherapy seems to provide a better survival response for pancreatic tumors discovered as a result of NSMJ. Doctors should know this rare and characteristic umbilical nodule correlated with a bad prognosis. Their clinical characteristics do not generally make it possible to differentiate them from the primitive lesions with the naked eye. But their superficial seat makes them accessible to a biopsy which can facilitate the diagnosis.

\section{DECLARATIONS}

\section{Authors' contributions}

Dr Mohamed Ali Chaouch: Participate in surgical treatment and writing the article.

Dr Asma Chaouch: Follow the patient in the outcome point Dr Karim Nacef and Dr Moez Boudokhane: Checked the article and supervised the patient's care.

\section{Conflicts of interest}

The authors have no conflict of interest to disclose.

\section{REFERENCES}


1. Abu-Hilal, M., \& Newman, J. S. (2009). Sister Mary Joseph and her nodule: historical and clinical perspective. The American journal of the medical sciences, 337(4), 271273.

2. Yendluri,V.,Centeno,B.,\&Springett,G.M.(2007).Pancreatic cancer presenting as a Sister Mary Joseph's nodule: case report and update of the literature. Pancreas, 34(1), 161164.

3. J., Jacques, L., Mesturoux, C., \& Vong, et al. (2014). Un nodule ombilical. La Revue de Médecine Interne, 1(35), 73-74.

4. Papa Souleymane Touré, Tall, C. T. , Pauline Dioussé, Adama Berthé, \& Ka, M. M.. (2015). Nodule de sœur mariejosèphe révélateur de carcinomes digestif et ovarien: à propos de 4 cas. Pan African Medical Journal, 22.

5. Khalfallah, M. , Chaker, Y. , \& Dziri, C. . (2011). Sister mary joseph's nodule showing adenocarcinoma of pancreas. La Tunisie médicale, 89(10), 790-791.

6. Gharaba, S. , Elfadil, K. , Samlani, Z. , Difaa, A. , Krati, K. , \& Elmahfoudi, A. , et al. (2011). Nodule de s?urmarie-joseph : quelles implications diagnostiques et thérapeutiques ? à propos de deux cas. Journal Africain d'Hépato-Gastroentérologie, 5(4), 276-279.
7. Chalya, P. L. , Mabula, J. B. , \& Peter F Rambau.... (2013). Sister mary joseph's nodule at a university teaching hospital in northwestern tanzania: a retrospective review of 34 cases. World Journal of Surgical Oncology, 11(1), 151.

8. Gilbert, J. D. , \& Byard, R. W. . (2016). Sister mary joseph's nodule: a very useful indicator of significant internal pathology. Forensic Science, Medicine, and Pathology, 12(1), 101-103.

9. Zhou, Wang, Gao, Bu, Zhang, \& Wang. (2014). Cutaneous metastasis from pancreatic cancer: a case report and systematic review of the literature. Oncology Letters, 8(6), 2654-2660

10. Lau, Melvin K., Davila, Jessica A., \& Shaib, Yasser H. . Incidence and survival of pancreatic head and body and tail cancers. Pancreas, 39(4), 458-462.

11. Ozaki, N. , Takamori, H. , \& Baba, H. . (2011). Sister mary joseph's nodule derived from pancreatic cancer. Journal of Hepato-Biliary-Pancreatic Sciences, 18(1), 119-121.

12. Bai, X. L., Zhang, Q., Masood, W., Masood, N., Tang, Y., Cao, C. H. \& Liang, T. B. (2012). Sister Mary Joseph's nodule as a first sign of pancreatic cancer. World Journal of Gastroenterology: WJG, 18(45), 6686. 